\title{
Takotsubo cardiomyopathy caused iatrogenic thyrotoxicosis
}

\author{
Lana Maričić ${ }^{1,2}$, Sandra Makarović ${ }^{1,2}$, Kristina Selthofer-Relatićc ${ }^{1,2}$, Krešimir Jelić ${ }^{1}$, Robert \\ Steiner ${ }^{1,2}$ \\ 1. Department of Cardiovascular Diseases, University Hospital Osijek, Osijek, Croatia. 2. Faculty of Medicine, University \\ J.J. Strossmayer Osijek, Osijek, Croatia.
}

Correspondence: Lana Maričić. Address: Department of Cardiovascular Diseases, University Hospital Osijek, J. Huttlera 4 Osijek, Croatia. Email: lana.maricic@gmail.com

Received: February 26, 2015

DOI: $10.5430 /$ crim.v2n2p82

Online Published: April 27, 2015

URL: http://dx.doi.org/10.5430/crim.v2n2p82

\section{Abstract}

The patient was a 34-year-old woman presented to the emergency department with a chest pain. During the last two years she took replacement therapy with levothyroxine because of lymphocytic thyroiditis. The ECG upon admittance verifies tall $\mathrm{T}$ waves in the precordial leads and the subsequent ECG shows a negativation of the $\mathrm{T}$ wave in the precordial leads. In the patient's echocardiographic findings, dyskinesia of the apical anterior segment is found, in laboratory findings increased levels of cardioselective biomarkers are present. Afterwards, a coronary angiography is done and no significant stenosis was detected in any coronary arteries, and ventriculography showed hypokinesia anterior mid segments. Considering all this, the diagnosis of Takotsubo cardiomyopathy is set, iatrogenically caused by thyrotoxicosis in combination with the recent Caesarean section.

\section{Keywords}

Takotsubo cardiomyopathy, Thyrotoxicosis

\section{Introduction}

Takotsubo cardiomyopathy, also known as the broken-heart syndrome, was described by scientists in Japan in the beginning of the nineties. It is characterized by akinesia or dyskinesia of the apical or middle ventricular segment with the absence of obstructive coronary artery disease, pheochromocytoma or myocarditis (Mayo criteria) ${ }^{[1]}$. The syndrome is accompanied by a newly created ST-segment elevation or T wave inversion, with a moderate increase of the cardiac biomarkers. It is often associated with intense emotional and psychological stress. Among the factors that are important in the induction of Takotsubo cardiomyopathy are an acute exacerbation of COPD, thyrotoxicosis, Addison's crisis, general anesthesia, septic shock, anaphylaxis, acute cholecystitis, acute pancreatitis, pregnancy, cerebrovascular disease ${ }^{[2]}$. The appearance of Takotsubo cardiomyopathy is predominantly described in postmenopausal women and in $5 \%-11 \%$ of cases it occurs in women younger than $50^{[3,4]}$.

\section{Case presentation}

The patient was a 34-year-old woman presented to the emergency department with a chest pain that had lasted for two hours. The chest pain started during a normal physical activity. The patient has not been more seriously ill. Her history 
revealed medically controlled chronic lymphocytic thyroiditis and she has been taking a replacement therapy with levothyroxine at the dose of $75 \mathrm{mcg}$. The last control of the thyroid hormone was a few months ago, during pregnancy. She has had two births by Caesarean section and the last was ten weeks ago. Immediately upon the admit of the patient, she underwent physical examination and an anamnesis was taken, then an electrocardiogram and a complete laboratory analysis were made. Electrocardiography (ECG) upon admittance verifies tall $\mathrm{T}$ waves in the precordial leads (see Figure 1A) and repeated ECG shows a negativation of the T wave in the precordial leads (see Figure 1B). In the patient's echocardiographic findings, dyskinesia of the apical anterior segment is monitored. In laboratory findings, increased levels of cardioselective biomarkers (creatine kinase 78-155-218 U/L; creatine kinase-MB 15-28-40 U/L; troponin I 1,00716.164-16,640- 13.258 to $8.503 \mu \mathrm{g} / \mathrm{L}$ ). Afterwards, a coronary angiography is done by which clear test results of epicardial arteries are determined, and ventriculography shows hypokinesia anterior mid segments (see Figure 2). The subsequent laboratory findings of thyroid hormones have determined thyrotoxicosis (FT4 35 pmol/L; FT3 7.25 pmol/L; TSH $0.008 \mathrm{mIU} / \mathrm{L}$; anti TPO $>7500 \mathrm{IU} / \mathrm{mL}$ ) and levothyroxine is excluded from the therapy. The combination of history, ECG changes, echocardiographic findings, and a normal finding of coronary blood vessels, as well as in similar studies, indicates Takotsubo cardiomyopathy diagnosis ${ }^{[5]}$. Considering all this, the diagnosis of Takotsubo cardiomyopathy is set, iatrogenically caused by thyrotoxicosis in combination with the recent Caesarean section. While hospitalized, the patient was treated with a beta blocker, the angiotensin-converting enzyme inhibitor. During the following period the patient is hemodynamically stable, without chest pain. She has been followed at the outpatient clinic regularly and the subsequent echocardiogram showed no excesses in contractility, and the ECG showed no scar formations.

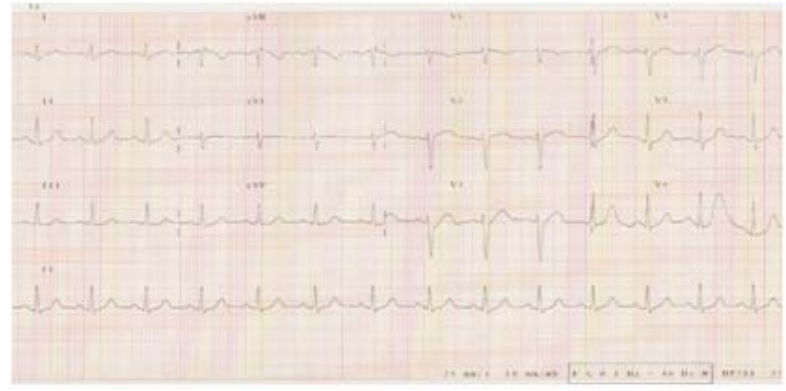

Figure 1A. ECG on the admission

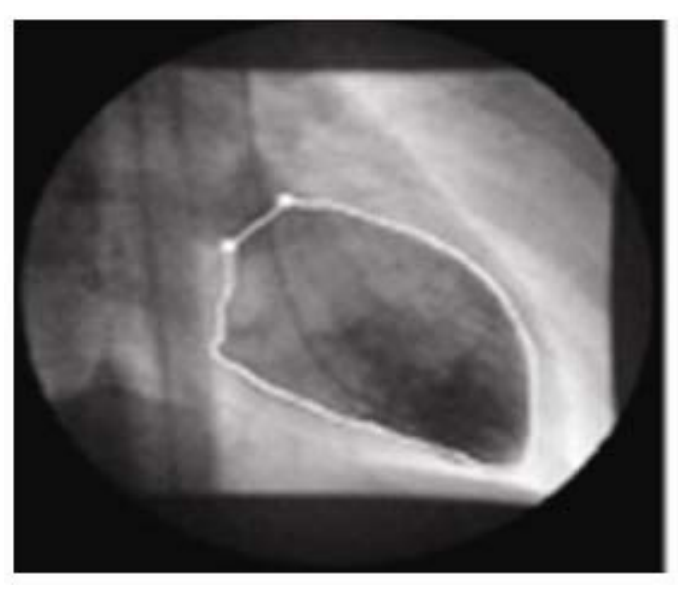

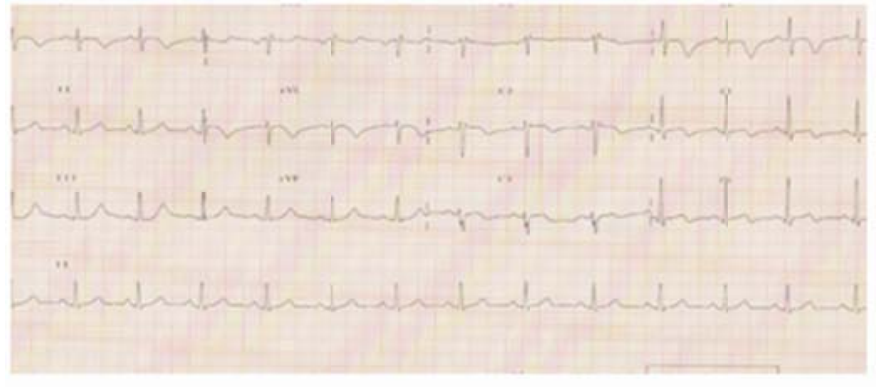

Figure 1B. Repeated ECG after 6 hours

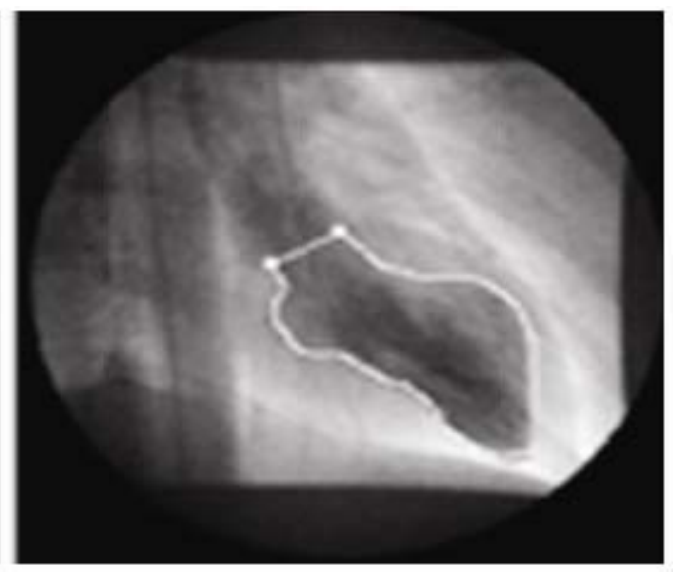

Figure 2. Ventriculography shows hypokinesia anterior mid segments 


\section{Discussion}

Pathophysiology of Takotsubo cardiomyopathy is not completely clarified. The most common theory talks about coronary vasospasm, microvascular dysfunction ${ }^{[6]}$. In patients, an increase of catecholamines was determined compared to patients with myocardial infarction, which justifies the belief that stress is one of the key triggers for this type of cardiomyopathy. The effect of thyroid hormone on the heart is evident at several levels, thus it simultaneously affects the heart rate, myocardial contractility, peripheral vascular resistance, and at the same time they are responsible for the expression of structural and regulatory genes in myocytes ${ }^{[7]}$. The combination of iatrogenically caused thyrotoxicosis (taking levothyroxine), physical stress (the recent birth by Caesarean section) and emotional stress (a working mother of two children) resulted in transient left ventricular dysfunction. The pathophsiology of Takotsubo cardiomyopathy in this case is a combination of physiological stress and thyrotoxicosis. The physiological stress leads to the activation of cortisol, catecholamines and cytokine that affect contractility of the myocardium. Simultaneously, elevated levels of FT3 in combination with the aforementioned pathophysiological mechanisms themselves significantly affect the structure and function of the myocardium. Certainly, the adrenergic system plays a key role in the development of stress-induced cardiomyopathy.

\section{Conclusion}

This case confirms that the presence of two factors, iatrogenically caused thyrotoxicosis and a recent Caesarean section which led to an increase in the levels of catecholamines, increases the risk for the development of Takotsubo cardiomyopathy in younger women, although it predominantly occurs in elderly women.

\section{References}

[1] Prasad A, Lerman A, Rihal CS. Apical ballooning syndrome (Tako-tsubo stress cardiomyopathy): A mimic of acute myocardial infarction. Ann Intern Med. 2004; 141: 858-65. PMid:15583228

[2] Gianni M, Dentali F, Grandi AM, et al. Apical ballooning syndrome or takotsubo cardiomyopathy: A systemic review. Eur Heart J. 2006; 27:1523-29. PMid:16720686 http://dx.doi.org/10.1093/eurheartj/eh1032

[3] Bybee KA, Kara T, Prasad A, et al. Systemic reciew: Transinet left venntricular apical balooning: A syndrome that mimics ST-segment elevation myocardial infarction. Ann Intern Med. 2004; 858-65. PMid:15583228 http://dx.doi.org/10.7326/0003-4819-141-11-200412070-00010

[4] Patel Sm, Chokka RG, Prasad K, et al. Distinctive clinical characteristics according to age and gender in apical ballooning syndrome (takotsubo stress cardiomyopathy): An analysis focusing on men and young women. J Card Fail. 2013; 19: 306-10. PMid:23663812 http://dx.doi.org/10.1016/j.cardfail.2013.03.007

[5] Kurisu S, Kihara Y. Diagnosis and management of takotsubo cardiomyopathy. Intern Med. 2015; 54(1): 1-2. PMid:25742885 http://dx.doi.org/10.2169/internalmedicine.54.3454

[6] Pernicova I, Garg S, Bourantas CV, et al. Takotsubo cardiomyopathy: a review of the literature. Angiology. 2010; 61(2): 166-73. PMid:19625263 http://dx.doi.org/10.1177/0003319709335029

[7] Irwin Klein, Sara Danzi. Thyroid Disease and the Heart. Circulation. 2007; 116: 1725-35. PMid:17923583 http://dx.doi.org/10.1161/CIRCULATIONAHA.106.678326 